\title{
Finding Our Way Through a Pandemic: Teaching in Alternate Modes of Delivery
}

\author{
Edward R. Howe* and Georgann Cope Watson \\ School of Education, Faculty of Education and Social Work, Thompson Rivers University, Kamloops, BC, Canada
}

OPEN ACCESS

Edited by:

Tara Ratnam,

Independent Researcher,

Karnataka, India

Reviewed by:

Hafdís Guðjónsdóttir,

University of Iceland, Iceland

Luciana Venâncio,

Federal University of Ceara, Brazil

Christi Underwood Edge,

Northern Michigan University,

United States

*Correspondence:

Edward R. Howe

ehowe@tru.ca

Specialty section:

This article was submitted to

Teacher Education,

a section of the journal

Frontiers in Education

Received: 30 January 2021

Accepted: 10 May 2021

Published: 24 May 2021

Citation:

Howe ER and Watson GC (2021) Finding Our Way Through a Pandemic:

Teaching in Alternate Modes

of Delivery.

Front. Educ. 6:661513.

doi: 10.3389/feduc.2021.661513
The COVID-19 pandemic caused a dramatic pivot to online learning and has forced teachers to critically re-evaluate teaching strategies. Thus, the questions, framing this selfstudy were: 1) How will I be able to do the learning activities I normally do in the classroom online including individual work, group activities, debates, and whole class discussions? and 2) How will I be able to pivot my signature lessons to the alternate delivery model? This self-study of teaching and teacher education practices (S-STTEP) builds on previous research to transform traditional face-to-face lessons into effective online lessons using alternate modes of delivery. In this paper, Ted shares some of his signature lessons including ice-breakers, critical response questions, discussions, group activities, and jigsaws, utilizing Moodle, Big Blue Button, Padlet, Google Docs, and other online tools. With Georgann's help as a critical friend, Ted critically analyzed his teaching of Master of Education graduate students through S-STTEP. In addition, he explored comparative ethnographic narrative (CEN) as another way of knowing within the S-STTEP space. Data included detailed weekly reflections. In addition, students provided written feedback at the end of each class, and at the end of term through a survey and course evaluation. Ted shared weekly electronic journal reflections and student feedback with Georgann, via email and teleconferences. Then, together Ted and Georgann made meaning from these field texts. The research text evolved from teacher-to-teacher conversations. Promising pedagogies for synchronous and face to face learning were identified with several signature lessons the focus. Georgann, as Ted's critical friend helped confirm and verify the most significant results amongst the many interesting reflections made.

Keywords: narrative inquiry, self-study of teaching and teacher education practices, international students, COVID-19 pandemic, comparative ethnographic narrative

\section{INTRODUCTION}

In response to the COVID-19 pandemic, in March 2020, many universities across Canada and throughout the world suddenly switched from face-to-face instruction to alternate forms of delivery (sometimes called emergency remote instruction). All universities in the province of British Columbia (BC), in a unified decision and with an abundance of caution continued this practice into the Fall 2020 and Winter 2021 semesters. With the exception of a handful of courses with special circumstances, for example teaching practica, all courses at Thompson Rivers University (TRU) were offered online rather than face to face (f2f). The pivot from traditional classroom teaching to online teaching has had a profound effect on higher education and on instruction. It has required 
instructors to drastically change their teaching strategies and to critically question common pedagogies of practice, prompting this study. The purpose of this self-study of teaching and teacher education practices (S-STTEP) is to continue what was started last year, to build on our previous research (Howe and Cope Watson, 2020) and to find new ways of delivering lessons. As author and critical friend, we continue to collect data in the same way but focus on comparing new approaches demanded by alternate delivery modes with traditional "tried and true" activities and lessons. Thus, this is both a self-study and a comparative study.

Recently, there has emerged a plethora of research on the shift from $\mathrm{f} 2 \mathrm{f}$ teaching to alternate delivery in all contexts of teaching and learning. Not all of this research is academic peer reviewed research, as the timeline to publish research does not align with the urgency of this new reality. However, this is changing and the research on the pivot to online learning is emerging gradually. This study focuses on teaching in higher education drawing on both the scholarly research and additional resources that have been published since the shift in March 2020 (CameronStanderford et al., 2020; Lederman, 2020; Loose and Ryan, 2020; Rapanta et al., 2020; Thompson, 2020).

At the site of this study, TRU, in BC, Canada, the pivot to alternate forms of delivery in March 2020, required faculty, parttime instructors, and sessional faculty to move their courses to online delivery with only days or weeks to prepare, and with little support from the overwhelmed Instructional Technology and Instructional Design departments. This created a significant additional workload, both in the way of designing a course in Moodle, our Learning Management System (LMS), and in designing learning activities and assessments to complete Winter 2020 courses. Courses were moved to alternate delivery with only three weeks remaining in the semester, and, while it was a challenge, it was nothing compared to what would come in the subsequent semesters. Spring, Summer, and Fall 2020 courses were also offered as alternate delivery, but Ted was not teaching in Spring or Summer 2020.

It is important to note that alternate modes of delivery are quite different from open learning or what would normally be considered distance or online learning. TRU has a wellestablished Open Learning (OL) division with thousands of students enrolled in various programs, studying from across the province, and all over the world. In fact, our university, the fourth largest in BC, is recognized as a leader in the field of distance education. TRU has many of the same course offerings in both $\mathrm{f} 2 \mathrm{f}$ and $\mathrm{OL}$. We are familiar with courses offered in OL and the particular ways that they have been constructed and are currently delivered. In fact, Ted has developed a course in OL taught by Georgann. It took well over a year and countless hours to get this course ready. Ted had a great deal of support from OL staff including a videographer and other specialists. Georgann also teaches graduate courses in both OL and our regular Master of Education (MEd) Program. So, we are well aware of the distinction between $\mathrm{f} 2 \mathrm{f}$, online learning, and what is currently being offered in alternate forms of delivery.

The Fall 2020 semester brought additional challenges. One of the challenges of the pivot was linked to uncertainty in enrollments, in particular for international students who were unable to obtain visas or had other delays in their registration. While some students were already in the country, others were abroad waiting for visa approval or pending travel restrictions. One Canadian website predicts that demand from international students will continue to fall due to high global unemployment rates, and slow economic growth across the globe (teachonline.ca). As approximately one fifth of TRU's students are international students, this prediction will likely impact course enrollments, and faculty deployment.

The pandemic resulted in Ted's Fall 2020 Comparative and International Education (CIE) course being cancelled at the last minute in mid-August. Instead, Ted offered to teach a course in the Graduate Certificate in Educational Studies (GCES). Like many other instructors, he had only a few weeks to prepare a new course, taught in a new way, exclusively in Moodle, the LMS available to faculty.

Ted decided to utilize many of his core lessons from his teaching toolkit and sought advice from Georgann and other colleagues as to how to revise activities for online instruction. Thus, this S-STTEP evolved from our previous self-study and the necessity to readily transform traditional lessons with the goal to engage students and to improve teaching. This research builds on the lessons that were the focus of our previous self-study, conducted in Fall 2019, and our ongoing collaborations (Howe and Cope Watson, 2020).

\section{RESEARCH QUESTIONS}

Prior to the first class held September 9, 2020, Ted identified the activities he wanted to develop and transform into alternate modes of delivery in preparation for his new online class. These included startup routines like self-introductions, people searches, and ice-breaker activities; small group work incorporating Think, Pair, Share (TPS), educational chronicles, and jigsaw activities; and critical response questions to engage students in both online and in class discussions (Howe and $\mathrm{Xu}$, 2013; Howe and Cope-Watson, 2020). Thus, Ted wanted to investigate how his core signature lessons, that have become part of his teacher toolkit, would require modifications in alternate delivery modes of instruction. Ted posed the following questions, framing this self-study:

How will I be able to do the learning activities I normally do in the classroom online including individual work, group activities, debates, and whole class discussions?

How will I be able to pivot my signature lessons to the alternate delivery model?

\section{LITERATURE REVIEW}

Graduate students are among the fastest growing population of students enrolling in online course and distance education programs due possibly to time constraints, scheduling conflicts and the flexibility of online education (Murdock and Williams, 2011 , p. 305). So, while many graduate students were already 
enrolled in online programs at the time of the sudden pivot to online learning due to the COVID-19 pandemic, those who had chosen $\mathrm{f} 2 \mathrm{f}$ instruction were forced into alternate delivery modes of instruction or emergency remote teaching. Given the dramatic timeline of recent events associated with this educational crisis, perhaps it is not surprising that there is a paucity of literature pertaining directly to alternate modes of delivery. Nevertheless, it is encouraging to see other teacher educators have begun to reflect on the implications to pedagogy and practice. These included a number of Frontiers articles (Siemens, 2005; Burns et al., 2020; Cameron-Standerford et al., 2020; Jones and Kessler, 2020; Thomas, 2020; Allo, 2020) as well as other peer reviewed articles (Johnson et al., 2020; McCormack, 2020; Prince et al., 2020; Rapanta et al., 2020). In addition, there has been a plethora of non-peer reviewed publications included in educational websites to support practitioners, administrators, and students as they seek success in alternate delivery modes of teaching and learning in higher education (Academic Matters, Canadian Digital Learning Research Association, CAUT, Educause, Every Learner Everywhere, Inside Higher Education, Online Learning Consortium, The Chronicle, TEACHONLINE). Even publishing companies have developed resources for alternate delivery teaching during the pivot (Pearson). To further support faculty, administrators, and students, most universities and colleges have developed web pages, blogs, webinars, presentations, and other professional development/student success resources to help with the pivot to alternate delivery. Despite the rapid development of the pandemic, knowledge mobilization is occurring at a remarkable pace, as these articles, publications, and websites have received much attention with thousands of downloads to date. Clearly, the switch to online instruction is a hot topic for higher education in 2021. The following literature review presents some of the current and contemporary emergent themes on alternate delivery modes of education in higher education. The literature is organized into themes: extending theoretical frameworks of online learning into alternate delivery, social, cognitive, and teaching presence in alternate delivery models, and tips and tricks for alternate delivery models.

\section{Extending Online Learning Theory Into Alternate Delivery Practice}

The theory of online teaching and learning theory has found a place in the scholarly work on distance education. The literature often refers to online learning, open learning, and learning through technology. Much of the literature builds on constructivist learning theory, an approach to learning that examines both cognitive constructivism as a way that learning is built upon previous and existing knowledge as per Piaget, and social constructivism as a way that learning is collaborative and collective as per Vygotsky. Connectivism learning theory extends constructivist learning paradigms into the digital spaces. Connectivism, first proposed by Siemens (2005) and Downes (2005) and later built up by Goldie (2016) suggests that digital learning technologies support learning through connections, networking, and technology. The idea emerged with the Web
2.0, now commonly known as social media, an online space where individuals or groups meet to share interests, ideas, news, and dialogue. More recently, the idea of connectivism suggests that students learn collectively and collaboratively with others, through technology in a global context. New information is easily accessed and through connecting with technologies, students can apply a heuristic approach to problem solving that is immediate, and collective (Downes, 2005). However, connectivism requires communities of learners as spaces for collaborative and collective knowledge building.

Community as a concept in online learning has become important in the theorization of online teaching and learning. Garrison et al. (2001) presented the Community of Inquiry (COI) model to frame the concept of presence in online teaching. Cognitive presence is characterized by the ways in which students construct meaning through reflection and dialogue. Social presence is characterized by the ability of participants to identity with a community of learners or a community of practice including peers and teachers. Teaching presence is characterized by the pedagogical design of cognitive and social processes to support students as they strive to meet course learning outcomes. Garrison et al. propose that this triangulated approach to teaching online supports positive online learning environments and is crucial to the learning experience. The COI framework is often cited in the literature.

As online learning took hold in higher education, the concept of online learning communities, grounded in a constructivist pedagogical approach, and the idea that learning is both collaborative and collective grew as a strong foundation of the theory of online teaching, and learning (Murdock and Williams, 2011). A sense of community encourages sharing, and studentstudent, and teacher-student relationships. A safe online learning environment can also enhance positive student learning outcomes (Murdock and Williams, 2011). Communities of practice is another concept that has been examined in online learning, where peer relationships, and networks can facilitate interactive learning. In communities of practice, the responsibility for interactivity is shared between both students, and teachers (Murdock and Williams, 2011). The online setting can create challenges for creating a safe environment for developing online communities and online communities of practice. Murdock and Williams (2011) found that students enrolled in online classes perceived it was the role of the instructor to create a safe online learning community.

\section{Social, Cognitive, and Teaching Presence}

Prince et al. (2020) studied active student engagement in university-level STEM courses. They found that social presence and teaching presence were significant factors in maintaining student engagement. For example, regular interactions between students and teachers should be embedded into every course including formative assessments, and feedback to which instructors should respond immediately. They also found that student resistance to active engagement should be anticipated, and that course instructors should prepare for this, and take steps to increase active participation. Online classes benefit from clear learning outcomes, explicit instructions 
around learning activities, shared grading rubrics, and ongoing formative feedback. Prince et al. (2020) make three recommendations: establish teaching presence and social presence early in a course and maintain them throughout ( $\mathrm{p}$. 13); make your expectations clear to students (p. 15); and anticipate student resistance and take steps to minimize it or eliminate it (p. 17). The literature also suggests that during the pivot to alternate delivery, faculty in higher education did not have the skills or knowledge to meet the new challenges of online teaching.

Rapanta et al. (2020) in their collaborative narrative research recognize that many university teachers did not have the pedagogical content knowledge related to designing and delivering online learning when the pivot was enacted. Their study collected responses on five questions from expert online teachers with the goal to help non-expert university teachers meet the sudden and immediate demand for online teaching. The authors acknowledge that the challenges non-expert teachers face emerge from shortcomings in planning and organization, as well as the knowledge of online teaching and learning principles required to create meaningful online learning experiences. The qualitative study asks the experts a series of questions, with the object that each expert's responses will resonate with some university teachers.

A summary of the experts' responses suggests that the organization of learning activities is crucial to the success of an online learning experience. These activities may be synchronous or asynchronous, and offline, but instructions are crucial, and must be clear, and succinct, ensuring that the learning activities are accessible to all students. The authors also found that the concept of presence (Anderson et al., 2001), including cognitive presence, social presence and teaching presence could be re conceptualized in the COVID-19 situation (Rapanta et al., 2020).

\section{Faculty Perspectives}

In a self-study Thomas (2020) cites the COI as important to building an online community. Thomas designed a self-study with the intent of "coming to know the personal, practical and pedagogical needs of my [sic] pre-service teachers as learners-and in particular online learners-during the Coronavirus pandemic" (p. 1). Using the COI as one of three conceptual frameworks, Thomas proceeds with a student questionnaire to flush out the tensions that influenced both online course design, and instructional approaches during the pivot.

Jones and Kessler (2020) explored the concept of care of self for teachers during the COVID-19 era. A narrative approach collected stories from the authors to highlight their experiences as a way of bringing teacher's work to the forefront of the contemporary discourse and raise awareness of the complexity of their work. They found that teachers felt worried, frustrated, overwhelmed, and many other emotions during the pivot. Similarly, Cameron-Standerford et al. (2020) interviewed faculty regarding their perceptions and experiences of the shift to emergency response instruction compared to their previous experiences with online teaching, the role of rigour and care in the curriculum, and the capacity to demonstrate care to colleagues. They acknowledge that preparation time to organize an online course is crucial to align course objectives with content and learning activities. Loose and Ryan (2020) also designed a study to explore how they, as first year faculty, navigated the challenges, and the learning opportunities they faced during the Spring 2020 semester. Their findings suggest that there needs to be a continuous practice of evaluating instructional practices, of equalizing student teacher relationships, and of allowing for alternate ways of representation in student work. Themes that emerged in their study include: innovation in survival mode, reimagining instructions, and reimagining connections. These themes resonate with Garrison et al. (2001) ideas of cognitive presence, social presence, and teacher presence.

With an underlying view towards rigour and care, CameronStanderford et al. (2020) designed a mixed methods study to "explore the initial perceptions and lived experiences of faculty whose classes were moved to an online/distance delivery as a result of the COVID-19 pandemic" (p. 4). They found that most faculty had competence with the LMS (Moodle). They also asked participants to rank a list of words describing their emotional response to the pivot to online learning. Challenging was the most frequently used word (15 times), followed by concern (14 times), anxious (10 times), stressful and relieved (8 times each). Other words included overwhelmed (7 times) and hopeful (7 times).

Faculty also identified a number of concerns associated with rigour. For example, there were concerns over specific actions around course objectives, learning activities, and assessments. Modifications to the online learning environment were cited as a necessary point of action. Questions about synchronous vs. asynchronous, interaction, and attendance were raised. This is also resonate in the literature by Garrison et al. (2001) about cognitive presence, social presence, and teacher presence.

The concept of care for students, and for self also emerged in the findings of this study. One participant in the CameronStanderford et al. (2020) study exclaimed: "In times of crisis we need to accept less-than-perfect teaching experiences. The sooner we accept that, the more we can help each other" (p. 7). The study goes on to share some of the strategies faculty employed to demonstrate care in the emergency remote teaching model. Many of these strategies are well-aligned with the literature on presence and community in the online learning and teaching environment (Garrison et al., 2001).

\section{Student's Perspectives}

Coman et al. (2020) analyzed student perceptions of the sudden pivot to online learning, through an online survey and semistructured questionnaire. The results revealed that the universities were not prepared for the pivot, and as such, the advantages normally associated with online learning were significantly diminished, allowing the disadvantages to become more prominent. Technical issues including frequent problems with technology while online, multiple platforms to learn, and lack of adequate technologies for students. The issues with technology are not often cited in Garrison et al. (2001) work but were strongly cited in this study. Issues related to teachers lack of technical skills included a lack of applying tools available in the 
LMS and a lack of interest in improving skills, and disorganization. Pedagogical issues emerged including some teaching styles that did not transfer well to the online learning environment. For example, an unbalanced teaching style with too much time on theory vs. practical tasks, or alternatively, too little or too much time on tasks. Students also cited a lack of clear instructions and expectations. Finally, students reported there was not enough interaction with either classmates or teachers.

For students, the inability to organize how they study and their time can be demotivating. Students also cite the lack of $\mathrm{f} 2 \mathrm{f}$ contact with classmates and faculty may create a feeling of isolation and interrupt student learning outcomes. Similarly, Thomas (2020) found that students were struggling at the beginning of the pivot, mourning the disruption of their academic support structures. Students reported that motivation was interrupted by a lack of routine of going to class, through in-class reminders and access to campus life. However, for some students, the flexibility of selfpaced study and self-disciplined learning were positive influences on the experience.

The loss of connection to faculty, other students, and campus is cited as a negative factor in both studies by Coman et al. (2020) and Thomas (2020). Thomas found that the concept of loss included "human connection, in-person connection, in-person lectures and hands-on-learning" (p. 8). Students also cite negative impacts on physical health including a lack of time outside, a lack of physical activity, and consequences of too much screen time (Coman et al., 2020). The findings in these two studies are linked to the COI framework, which stresses the important of presence in the online learning community.

\section{Teaching Strategies for Alternate Delivery Models}

All of the studies reviewed in the recent literature cite a need for presence in the alternate delivery mode (Cameron-Standerford et al., 2020; Coman et al., 2020; Jones \& Kessler, 2020; Murdock and Williams, 2020; Prince et al., 2020; Rapanta et al., 2020; Thomas, 2020). Strategies are cited in some of the peer reviewed literature to support the pivot. Only some studies cite the theoretical frameworks underpinning the pedagogy of online teaching and learning. This is a clear gap in the literature, but is not unexpected because most faculty who had to shift to alternate delivery have never studied or practiced online teaching. Strategies are, however, abundantly available, and while they may not be fully grounded in online teaching theory, they can be helpful. For example, support networks including Academic Matters, Canadian Digital Learning Research Association, CAUT, Educause, Every Learner Everywhere, Inside Higher Education, Online Learning Consortium, and TEACHONLINE have all published sets of tips and tricks to support teachers in higher education cope with the pivot to online delivery. Furthermore, most institutions have their own support centers for teaching and learning, and offer tips, workshops, webinars, and live support. As the pivot to alternate delivery modes proceeds into the Summer 2021 semester it can be anticipated that more research will emerge and will contribute to the theorization of the pedagogy of online teaching and learning.
The literature in this review is limited as this analysis and inquiry is only emerging. There is not much Canadian content in the literature, but this should change as the research becomes forefront in education. In sum, it is expected the scholarly work on the sudden shift to alternate forms of delivery will help to inform our professional practice in higher education.

\section{CONCEPTUAL FRAMEWORK: S-STTEP AND COMPARATIVE ETHNOGRAPHIC NARRATIVE}

The origins of self-study stem from the seminal work of Joseph Schwab (Craig, 2008; Craig and Curtis, 2020). Indeed, self-study has proven a natural fit for teacher educators (Loughran, 2007). Dewey (1938) and Connelly and Clandinin $(1988,1990)$ have greatly influenced our teaching philosophy (see, e.g., Clandinin 2000; Clandinin 2007; Clandinin and Connelly 2000; Clandinin et al., 2006). Furthermore, Schwab, (1983) curriculum grounded in four commonplaces: teacher, learner, subject matter, and milieu, also resonates with us as practitioners. S-STTEP research complements narrative inquiry (Loughran et al., 2004; Kitchen, 2009; Kosnik and Beck, 2010). Comparative ethnographic narrative (CEN) as a form of narrative inquiry is a qualitative approach to self-study that goes beyond narrative to explore reflexive turns. A critical friend provides the means and is essential to our reflexivity. This study combines S-STTEP and CEN to explore the research questions in a holistic way. While CEN is something Ted has been using since his doctoral studies (Howe, 2005), self-study was discovered by Ted only recently. Georgann as an experienced self-study scholar and as critical friend has helped Ted learn how to use S-STTEP which was then incorporated into his CEN conceptual framework.

\section{S-STTEP}

The most comprehensive and up-to-date reference in self-study, the S-STTEP handbook went to press before the COVID-19 pandemic (Kitchen et al., 2020). Moreover, none of the articles deal explicitly with alternate forms of delivery. Nevertheless, there are some significant and noteworthy contributions that are particularly timely and relevant to our current self-study. Vanassche and Berry (2020) as well as Craig and Curtis (2020) poignantly (and serendipitously) identified this time as a pedagogical turning point or "threshold opportunity" for selfstudy researchers. In tracing the conceptual underpinnings of S-STTEP, a number of theoretical "turns" have taken place including a turn from formal knowledge to practical knowledge, shifting self-study focus from epistemology toward “ontology” (Vanassche and Berry (2020), p. 7).

Vanassche and Berry (2020) identifies a threshold, or turning point, in S-STTEP evolution, where it is time to move beyond supporting teacher educators, and to extend knowledge sharing into other disciplines external to the self-study community. Further, Garbett et al. (2020) also identify a need to begin to disseminate S-STTEP research into other disciplines. Similarly, Butler and Branyon (2020) found in their systematic review of S-STTEP research that the scope of self-study is restricted to a 
small group of researchers in seemingly small clusters. And, Vanassche and Berry (2020) call to distribute knowledge through S-STTEP research to other communities within our professional field. Since many faculty, part-time instructors, and sessional teachers have been forced to move to alternate delivery models, there seems to be an inherent link to sharing knowledge of teaching practices through sharing S-STTEP studies on the specific challenges of the shift to alternate delivery resulting from the global pandemic.

The essential foundations of self-study have been wellarticulated by Vanassche and Berry (2020) including a major insight into "the value of knowledge, of and for, teaching and learning about teaching ... [making] clear why research in the field matters to teacher education policy, practice, and theory." (Loughran, 2020, vi). Building on the work of LaBoskey (2004), Vanassche and Berry (2020) summarize five characteristics of self-study methodology, stating that S-STTEP starts and ends with teacher education practice; speaks to a broad understanding of "improvement" in teacher education; is situated inquiry; is intentional and reflective; and is interactive (p. 9).

Questions about validity and trustworthiness with S-STTEP research have been addressed in the research. Qualitative researchers contend that self-study can be done with just as much rigour as any other methodology in social science. Furthermore, the information gained through the depth of analysis and richness of detail far surpasses any gains in external validity and reliability eschewed by survey methods. Stewart (1998) posits adapting the conventional positivist criteria for rigorous empirical research by replacing validity, reliability, and generalizability with more suitable ethnographic constructs. Validity (excluding external validity) becomes veracity (power of conveying or perceiving truth); reliability (excluding consistency) becomes objectivity (alertness, receptivity to the views of others, empathy, and openmindedness); and generalizability becomes perspicacity. Bullock, 2020 navigation of these pressures associated with self-study and his call "to give way to new experiences, new ideas and shifting pressures, and the ontological demands of a robust reflective practice" (p. 265) further our understanding of self-study as a legitimate methodology. Nevertheless, some scholars continue to question the trustworthiness of self-study and other forms of interpretive research. Hamilton et al. (2020) tackle trustworthiness of self-study research by situating concepts of quality and trustworthiness within other qualitative research designs. They also call attention to the value of studying one's own practice (p. 299-338).

Critical friendship can provide further rationale for the trustworthiness of self-study (Schuck and Russell, 2005). Bullock (2020) noted that there are two major considerations in self-study methodology: critical friendship and collaboration. "A critical friend, can help to review data, challenge assumptions, and suggest additional perspectives" (Mena and Russell, 2017, as cited in; Bullock, 2020, p. 249). A critical friend has to ask questions and push the researcher, while at the same time be a supportive collaborator. Samaras and Sell (2013) argue that critical friends should "provoke new ideas and interpretations, question the researcher's assumptions, and participate in open, honest, and constructive feedback" while acknowledging that "the structure and pedagogy of critical friend work can be problematic" (p. 97).

Furthermore, S-STTEP researchers acknowledge that our work is "always partial and emerging"... "bringing forward the actual, lived experiences of teacher educators in ways that can productively challenge and inform the dominant narratives of educational practice and research" (Vanassche and Berry (2020), p. 9).

\section{Comparative Ethnographic Narrative (CEN)}

In the early 1990s, as a novice teacher working in Japan, I became intrigued by comparative and international education. Then, a decade later, as a graduate student, I was introduced to narrative inquiry. These two elements have framed my evolving conceptual framework. Comparative ethnographic narrative (CEN) (Howe, 2005, Howe, 2010) is a blend of reflexive ethnography (Etherington, 2006) and narrative inquiry (Clandinin and Connelly 2000). Essentially, CEN is a collaborative narrative inquiry-comparative (as it involves comparing one's experiences with others); ethnographic (in situ, long term participant-observation); and narrative (incorporating peer to peer extended conversations). It is a form of self-study, joint autoethnography or other forms of collaborative, interpretive research (Ellis and Bochner, 2000; Loughran, 2007). CEN unearths fertile, descriptive narrative data. The CEN cyclical process of telling stories, reflecting on stories and re-telling stories with a coresearcher or critical friend, helps facilitate interpretation, and deep analysis, to uncover rich lived experiences. CEN resonates with me as a teacher. As a reflexive practitioner, it makes perfect sense to share our teaching experiences with colleagues in an effort to improve. Moreover, CEN draws on oral traditions, story telling, and forms of narrative inquiry that have been used for millenia.

Recently, I have begun to think that my conceptual framework of CEN is not only a sub-species of narrative inquiry but is in fact a form of self-study. CEN is well-aligned with S-STTEP to go beyond storytelling and to facilitate reflexive turns (LaBoskey 2004; Loughran 2010; Bullock and Peercy 2018). CEN meets LaBoskey, (2004) criteria of S-STTEP: "it is self-initiated and focused; it is improvement-aimed; it is interactive; it includes multiple, mainly qualitative methods; and it defines validity as a validation process based on trustworthiness" (p. 817). Moreover, I embrace the notion that "self-study researchers need to move beyond individual stories in which they have made a reflexive turn and toward an explanation of how such a turn changes their practice and contributes to research more broadly" (Bullock \& Peercy, 2018, p. 21). Thus, S-STTEP and CEN are well suited to improving our teaching. Moreover, S-STTEP and CEN are both theoretical and methodological frameworks.

\section{METHODOLOGY}

Upon ethic review board approval from our university, and with informed consent from students, Ted collected data on his teaching in Fall 2019, and then again in Fall 2020. Weekly 
reflections and teacher-to-teacher conversations with Georgann as a critical friend, resulted in more than 50 pages of data each year, including several pages of text per lesson, detailed student feedback, photos, and audio files. In early January, the course evaluation arrived, completing the data set-prompting us to begin data analysis.

This study applies a reflective process through a collection and thematic analysis of data from four lenses: self, colleagues (critical friend), students, and the literature (Brookfield, 2017). The data was analyzed inductively using the constant comparative method (Glaser and Strauss, 1967). As Ted analyzed the data, with multicoloured highlighters in hand, we re-discovered themes that had emerged over the 13 weeks of classes. Furthermore, we came to realize that the focus of the study was indeed on Ted's signature lessons and the pivot to alternate modes of delivery through the unique lenses of self, students, and critical friend. We found the analytical framework used by Loose and Ryan (2020) helpful in connecting to the literature and trying to make sense of all our data. Their $4 \mathrm{Rs}^{1}$ Professional Inquiry Model: Recognition, Reflection, Reaction, and Results based on Moore (1989), Moore (2012) transactional distance theory for online learning resonated with our experience as teachers working in alternate delivery modes of instruction. "In this model, teachers recognize students' needs, and adjust instruction, reflect on lesson components, structure, and learning environments, and react by adapting and modifying practices. Through those actions we see results that demonstrate ways we moved our practice to work toward a common goal with clear learning intentions." (Loose and Ryan, 2020, p. 4). This is precisely what Ted did during the Fall 2020 semester. This reflexive self-study facilitated adapting teaching strategies in real time.

In this S-STTEP, Ted wrote detailed weekly reflections on his teaching of a new course in an electronic journal for 13 weeks. In addition, he reflected on written feedback from students, at the end of each class, and at the end of term through course evaluation. Ted shared his reflections and student feedback with Georgann via email, and teleconferences, periodically. Together, Ted and Georgann made meaning from the collection of data. Interpretive data from the field text was analyzed using Loose and Ryan (2020) Recognition, Reflection, Reaction, and Results framework. Thus, the research text evolved from our teacher-to-teacher conversations (Yonemura, 1982; Howe, 2010). Promising pedagogies for synchronous learning were identified as the over-arching theme with several signature lessons the focus. Georgann, as Ted's critical friend helped confirm and verify the most significant results amongst the many interesting reflections made.

The practice of critical friendship is an important part of the methods in S-STTEP research. Vanassche and Berry (2020) include interactivity as one of the five characteristics of the methodology. In this study, Ted drew on Georgann's

${ }^{1}$ Of course, Loose and Ryan, (2020) 4Rs model must not be confused with the 4Rs (Respect, Relevance, Reciprocity, and Responsibility) posited by Indigenous scholars and acknowledged in Canada's Truth and Reconcilation Commission (TRC, 2015). experience with S-STTEP research and on her experience as an online instructor. In this way, Georgann and Ted were able to move beyond the naivety of approaching their sudden and imposed role of being online instructors. Georgann is well-versed in the theory of online teaching and learning, and could see the gaps, and overlaps between $\mathrm{f} 2 \mathrm{f}$ practice and alternate delivery modes. For example, when Ted and Georgann reviewed Ted's reflections, Georgann could help probe deeper into the ways that simply shifting a f2f learning activity to an online learning activity might be either a pedagogical success or failure. In one instance, Georgann wrote: Can you speak about the workload of teaching online? This is so important and needs to be acknowledged. Ted responded: Workload, planning, stress, and feeling burned out at the end of a lesson ....We are all feeling "zoom fatigue". This is an example of how the theory of online teaching must be considered in any research that is exploring the challenges for teaching professionals. In another instance, Ted wrote: Things have settled down and most technical issues have been resolved. Georgann wrote: Another thought: a reminder to include challenges with technology. Last night the students were in breakout rooms, then, suddenly, I was kicked out of BlueJeans, and they were abandoned. It took quite awhile to sort this out. These two examples go beyond the literal learning activities and into the covert challenges of shifting from $\mathrm{f} 2 \mathrm{f}$ classrooms to online classrooms.

In the next example, Georgann shares her experience within an analysis of large group discussion in the online classroom. Ted writes: I have noticed that there is a tendency for a few students to dominate the discussions. I feel several factors impact the participation: 1) Internet connectivity and technology; 2) English speaking ability and confidence; 3) Cultural contexts. While I did call on a few students, some of my questions were met with silence. One student did not even have a "mic" icon on the screen. I did not hear a word from her, but I did see her video. It is apparent that while everyone is coming to class, completing assignments, participating in online discussions, some students are not confident to participate in a live discussion. This opened an exploration of the practice of having large group discussions, and how they seem to mirror the f2f classroom. After our dialogue, we realized that large group discussions in both contexts, typically reproduce systems of power, and privilege, privileging some voices over others. This initiated an important change in practice for both Ted and Georgann.

These examples are only a few of the important dialogues that occurred during our text and video exchanges. Critical friendship pushes thought, shares experience, and helps to build new knowledge collectively, and collaboratively. Critical friendship dialogue and analysis also serves to address issues of reliability, and validity in S-STTEP research. These examples embody the role of the critical friend: to ask questions, to collaborate, and to participate in open, honest and constructive feedback (Samaras and Sell, 2013).

\section{Findings: Promising Pedagogies for Synchronous Learning}

The research questions framing this self-study were: 1) How will I be able to do the learning activities I normally do in the classroom 
online including individual work, group activities, debates, and whole class discussions? 2) How will I be able to pivot my signature lessons to the alternate delivery model? In addition, further questions were raised. What are the implications of alternate modes of delivery for the future of teaching? How are these promising pedagogies resulting from our pivot to the COVID-19 pandemic helpful to our teaching? In a search for themes to connect all the promising pedagogies, I came to realize that a critical element in each of these lessons was connecting individual students, living, and studying in isolation all over the world, to others socially, in small groups, and to the whole class. Both teachers and students faced serious challenges in alternate delivery modes of instruction. But in our search for effective ways to engage students in their virtual learning environments, teachers, and researchers have an incredible opportunity at this time to learn from one another.

To answer the research questions and to prepare to teach my course, I began the semester by sharing my teaching toolkit, signature lessons, and questions with a number of colleagues, including Georgann. In particular, I was seeking ways to most effectively do individual work, group activities, debates, and whole class discussions online, and how to deliver my signature lessons in the alternate delivery model. As shown in Supplementary Table S1, the traditional f2f lessons and activities that needed to be transformed into alternate modes of delivery included start-up routines, class discussions, and small group activities. Several teaching strategies such as in-class writing, debates, and presentations were deemed too challenging to adapt to online lessons, and were thus abandoned. In particular, synchronous learning in a virtual environment posed the most significant challenge. During the course of teaching in Fall 2020, many detailed reflections were made including the myriad of challenges associated with the use of technology but Ted and Georgann decided to focus on the most promising pedagogies to actively engage students in learning, albeit $\mathrm{f} 2 \mathrm{f}$ or online. Thus, the signature lessons reported here are as follows: People Search Ice-breaker; Class Discussion and Bridge Jigsaw; and Educational Chronicle TRU Rivers. Georgann confirmed this focus in her first response to Ted's initial journal entry where he summed up by saying,

As in all interpretive studies, I am sure there will be plenty of other important "ah-ha" moments ... serendipity is the hallmark of this work! So, in this first reflection, I will not say anything further about what I expect to find, nor will I make any grand predictions other than to say, I am hopeful that there will be much to be learned from this experience. It will definitely help me to plan my OL course for CIE and I expect to improve my face-to-face teaching too. Georgann commented "I love this!" (Journal entry, September 24, 2020)

\section{People Search Ice-Breaker}

The first class is essential for developing rapport with students, for making them feel safe and secure, and for setting the tone. Traditionally, I have asked students to complete an Identity
(ID) card. I use these $4 \times 6$ index cards to keep track of student participation and to have weekly back-and-forth conversations with students. On the front side, they write their names and a weekly reflection in class. On the back, they provide a brief self-introduction. I respond in writing by making comments and connections. I use this information to create a people search activity for the next class. Sometimes, this people search is done on the first day but if I don't know the students well, it is less successful, and more generic. Nevertheless, the people search serves as an effective ice-breaker activity. This would normally be a one-page handout with a grid of squares with questions written within each square ("Find someone who ..."). Each square represents a potential student. Students have the task of meeting other students and engaging in a brief conversation. The objective is to get to know others and to connect with potential partners or group members for activities. However, in an online learning environment, with students spread all over the world, these sorts of activities pose a serious challenge. Clearly, there was no way to provide students with a one-page handout as one would do in a traditional classroom setting. The solution was to modify the people search activity to make it more suitable to an online classroom. Firstly, I asked students to do a self-introduction via the Moodle discussion forum. I provided them with my own example, including a picture. I encouraged students to do this prior to the first class. This enabled students to become familiar with Moodle and in particular to become proficient in using the discussion forum, which is an integral part of their learning. Also, in that way, I was able to quickly get to know each student and to create an effective people search activity, using the detailed self-introductions provided by students on Moodle. While a $4 \times 6$ index card is very handy for a $\mathrm{f} 2 \mathrm{f}$ class, it has a limited amount of space. In switching to online instruction and being forced to change my teaching strategies, I have discovered a better way to facilitate instruction and classroom management. While I may still use ID cards, I will likely continue to use Moodle rather than the ID cards to help generate the people search activity. The information shared by students in their selfintroductions on Moodle, enabled me to get to know them well, and to have a richer conversation with students. I made notes to myself next to each of their names in the class list, so that when we were online, I could easily remember facts about each of them. This facilitated our discussions as I was better prepared to engage them by making meaningful connections to each of them. Moreover, it helped students to get to know each other well during the first week because students could see other's pictures and read each other's self-introductions. This is evident in my reflections made after the first class:

My start-up was unlike any before. I worked hard to get my Moodle site up and running but it was very challenging to make it as comprehensive and detailed as usual, given the tight timeline. In any case, I am proud of the work put into this ... Instead of using ID cards, I asked students to do a self-introduction using the Moodle Forum, prior to our first class. I provided an example with my own self-introduction. I also uploaded a picture. 
This served several purposes: firstly, it was practice for our first class, where I asked each student to introduce themselves, and I spoke briefly to each of them. And it gave them the chance to become familiar with Moodle discussion forums. Finally, it gave me some data for a People Search Activity. Instead of my usual 1-page handout Ice-Breaker, I made notes to myself about each student and used that in our first class in the following way. I described each student and asked others to guess who I was describing by writing their name in the chat. Then, I got the student to self-identify and turn on their video camera and mic to do a selfintroduction, one by one. I feel this was an effective way to replace my ID Cards and Ice-Breaker in our digital world. In fact, I may continue to do this from now on as there some advantages to this digital way rather than the traditional pen and paper methods (Journal entry, September 10, 2020).

\section{Class Discussion and Bridge Jigsaw Activity}

In this signature lesson, I use a jigsaw activity to illustrate how to facilitate small group work and discussions both online and in a synchronous class. The term jigsaw comes from common teacher education practices. It is helpful for students (particularly international students for whom English is likely not their first language) to break up materials into more manageable parts, to give small groups a piece of the jigsaw puzzle, and then to have each group share what they have learned with the entire class. In this way, reading can be shared and interpreted together. The building bridges idea came to me in Fall 2019. I took a colleague's signature lesson and modified it to suit my paper on transcultural teacher development, building bridges between east and west (see Howe and $\mathrm{Xu}, 2013$ ). A knowledge tree, cut and paste jigsaw activity became a bridge metaphor, with structures of the bridge represented by major ideas of the paper. This lesson was highlighted in my previous self-study (Howe and Cope Watson, 2020). Whereas in the f2f class, I physically cut up the paper with each group of students getting a section to critically analyze, summarize, paste to poster paper, and share with the entire class on the white board, now it was accomplished using digital tools. I used the Big Blue Button (BBB) breakout rooms in Moodle to facilitate small group discussion and planning. Students then used Google Docs to bring together their group work (essentially the cut and paste part of the activity) and then uploaded their work to Padlet (https://padlet.com/). Instead of drawing a picture of a bridge, students chose an image from their own photos or from the Internet. Padlet enabled them to share their work and to comment on the work of others in a way that the white board could not facilitate. Students were asked to identify one main point, to summarize it, provide a quote and citation (bridge support), and then as a group, upload this as "Bridging Gaps" image to Padlet (see Figure 1). Finally, I asked them to please comment on others' contributions and to provide me with Feedback on Moodle. I reflect on the implications of this lesson below.
I opened up the BBB classroom 15 min early and greeted students as they arrived. This "checking in" helped to connect me to each of them and it served to ensure that microphones and cameras were working. I tried to ask each student something different like "How is the weather there?" or "What time is it there?" or I made a comment about their dog, "How old is your puppy?" and so on ... After checking in with all 15 students, I started the lesson ... I finished my lecture with a brief discussion on the reading, asking for students to respond to my questions posed. Then we moved into the Bridge Jigsaw group activity. I included the instructions and link to Google Docs in the slides. I also copied it into the chat. I asked students to indicate in the chat if they had used Google Docs before and many said "yes" which was good. Within $30 \mathrm{~min}$ I could see students were well on their way to completing the group activity. I was happy that Group 1 did their work in advance and had it finished before others had even started! Super keeners!! These students helped others to get going with the Google Docs. Within $2 \mathrm{~h}$, I could see that most group members had successfully made a contribution to Padlet (Journal entry, October 22, 2020)....

The online discussion over BBB went smoothly. I see plenty of evidence that students did the assigned reading (14/15 students had responded to the Critical Response Questions (CRQs) posed in the online discussion when I checked about an hour before class). Generally, students thought deeply about the questions raised. Some students went a lot deeper than others. So, I tried to praise those that went above the 100-word minimum and especially when they made personal connections. I added my own comments to their posts in my usual fashion.

In our $\mathrm{BBB}$ discussion, I encouraged students to use the chat function, to unmute and to use video whenever possible. Also, during my presentation of the paper, I attempted to engage students with lots of questions like "Where is that?" [Answer: Victoria]. Interestingly, in the chat, I saw that students made comments like "Victoria is the capital of BC." And "I thought Vancouver was the capital of BC!" I asked the First Nations student to give more details of the potlatch. But she said "We don't do potlatch." So, I asked her to describe similar traditions in her experience involving food. I was pleased in the way I was able to involve many students in discussion. I called on the student who had lived in South Korea to provide transcultural insights.

The synchronous lesson (lecture and discussion) went for $25 \mathrm{~min}$ as planned and then we moved into the BBB breakout rooms for $10 \mathrm{~min}$. Students were asked to share their responses to the CRQs. These questions were posted in Moodle, on the slides, and shared so each group could see the CRQs in the breakout rooms. I asked each group to identify one key point. Then, after the breakout rooms, we spent $20 \mathrm{~min}$ in whole class discussion. One student from each of the six groups shared their thoughts. In some cases, students were called upon but in most cases they volunteered. In this way, more than six students were able to participate in the discussions.

Our class discussion proceeded well with at least one speaker from each group. I feel that $20 \mathrm{~min}$ was enough time for this but 


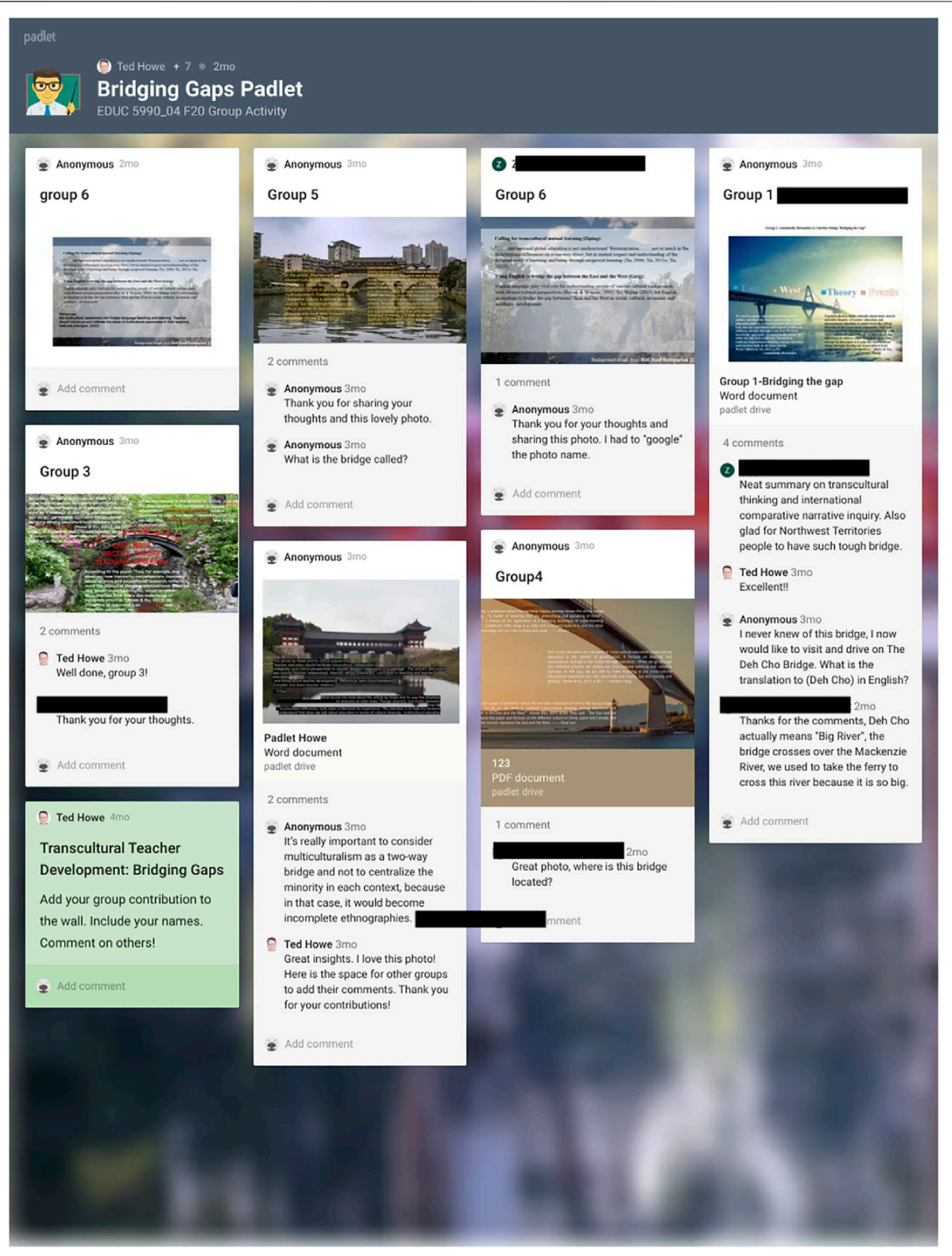

FIGURE 1 | Bridges jigsaw.

there were interesting topics raised that could have easily warranted more time. For example, R, an articulate Chinese student touched on cultural relativism and tried to make the point that for me as a Westerner to critique Japanese social, and cultural norms, it poses some critical questions about Western hegemony (this was one major point from the paper). He brought up geopolitical considerations, immigration, multiculturalism, and more. Another student, A, living in the Northwest Territories (NWT), pointed out that transcultural teachers can experience otherness without having to leave Canada (note: A is not from NWT but lives and teaches in Yellowknife, which has many Dene/Inuit First Nations). I called on J to comment on her perspectives as a sojourner to South Korea. Also, several students were able to share their opinions without me having to call on them directly.

Some very salient points were made. I was very impressed with the depth of their responses. I think part of this is due to the scaffolding nature of my class structure. Doing the readings and online reflections prior to the class is very important for our international students in particular. While some discussions tend to be dominated by students that are more capable and vocal, these include both domestic and international students. I have been impressed at how many students are able to contribute to our discussions. I spoke to nearly every student. After class, I 
checked the breakout rooms. I had a conversation with two students who were in the midst of planning their Padlet wall contribution. It was good to connect with $\mathrm{C}$ as she did not say anything during our class. Her partner, $\mathrm{J}$ is the more extraverted one.

Students genuinely like breakout rooms and appreciate the opportunity to interact with one another in a safe environment. This is evidenced in the feedback I received on Moodle:

Dear Ted, I do really enjoy the idea of breakout room which we did in this week class. Because I found students are more willing to say and to express their ideas in breakout room instead of in main room. And in breakout room, group members can exchange the ideas more deeply and, in more details (Student 1, October 13, 2021).

In a final reflection on lectures and discussions in our synchronous lessons, I also noted,

As I lectured, I stopped a number of times to ask some probing questions, asking for the "thumbs up" response. Students also used the chat function to ask questions or make comments. Actually, at the start, I told students that while I was calling this a lecture, I really wanted them to think of this more as a discussion. I encouraged them to ask questions by raising their hands or using the chat (Journal entry, November 26, 2020).

In an anonymous in-class survey of students (using Slido.com) at the end of the term, a majority (11/14) indicated that they had enough time to discuss readings with other students. Nevertheless, this is something I wish to improve.

\section{Educational Chronicle TRU Rivers}

As narrative inquiry is an integral part of my teaching and research, I have used educational chronicles in many of my classes over the past two decades, as I was first introduced to this pedagogy as a graduate student. I have found it an effective way to elicit students' education and experiences that have shaped their being. It was especially relevant in our GCES Research Colloquium course as I needed a meaningful activity to introduce students to narrative inquiry. Also, it provided a connection to the previous week's conference where one of the speakers shared a phenomenology study. Educational chronicles help individuals to reflect on both formal and informal experience and education. Students are asked to recall their most significant life-events and to share them with others. In its simplest form, it can be represented as a timeline from birth to present day, with formal education above and informal education below the line. Here is what was posted in Moodle to provide students with an anticipatory set.

Please click here to join our BBB virtual classroom. Today we will focus on education and experience. You will share your Educational Chronicle (see my example in Moodle) and do a Group Activity: TRU Rivers. Please upload your Educational Chronicle to https://padlet. com/edwardrhowe/trurivers
Today's Agenda
1) Conference de-brief
2) Educational Chronicles
3) TRU Rivers Activity on Padlet

Traditionally, in my f2f teaching, I would write "Today's Agenda" on the white board, so that students can see what we are doing as they enter the classroom. By posting this to Moodle, however, students can see what we are doing well beforehand. Also, it can be cut and pasted into the BBB chat to help remind both the teacher and students of our agenda during the lesson. This is an effective strategy in online synchronous learning but it is simply good teaching that could be used in either $\mathrm{f} 2 \mathrm{f}$ or online classroom environments.

I feel good about the fact my students appear more comfortable and relaxed. While we discussed things, I had an image displayed on BBB. It was the TRU Rivers example from last year, showing four streams of different colours flowing into TRU. Each stream represents a students' educational/experiential life journey. Next, I used screen share to show them my own educational chronicle (also posted to Moodle). I gave them examples of my formal and informal education and experience. I also used this opportunity to share some artifacts. I brought out my diary from 1976 to 1988. I told students that these diaries and other artifacts help us to remember our stories of experience. I encouraged them to reflect back on their own education and experiences. I also mentioned that I will ask them to share an artifact and story for our last class. I felt this was an effective way to introduce students to my teaching and research while making connections to each of them and to the subject matter. I told students that while the TRU Rivers Activity was done in groups using large poster paper, in our alternate delivery mode, I could not find a way to do it in exactly the same way, so I asked each student to create their own Educational Chronicle (by hand or using software of their choice), and to upload it to Padlet. I decided to give them the weekend to do this important task, rather than "due next day" as usual. Finally, I wrapped up the lesson by asking if they had any questions. As usual, a few students had questions like "Do we have to include as many incidents as you did?" I said, well, none of you are as old as I am, so, I guess not! (Journal entry, November 20, 2020)

In today's class, we reviewed last week conference, Ted teaches us what is Educational Chronicles and how to write it. Because it's a part of Narrative Inquiry and Phenomenology. And this is consistent with the topic of this lecture (Student 2, November 18, 2020).

Through this class I understand what is chronicle and how we do this. Others can know us through chronicle. This is a really good way to let others know us quickly (Student 3, November 18, 2020). 


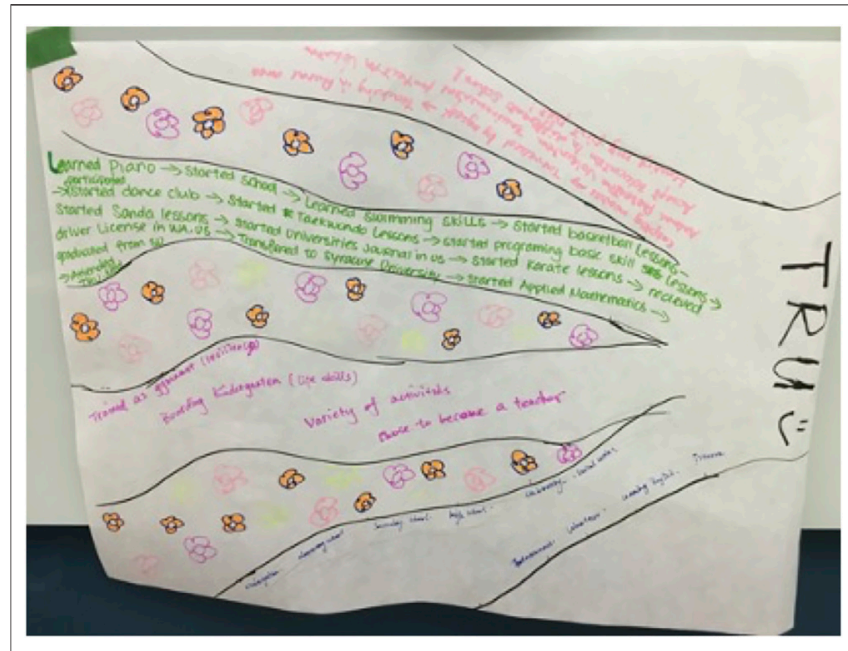

FIGURE 2 | Educational chronicle TRU rivers 2019.

I include an example of the Educational Chronicles TRU Rivers activity from Fall 2019 (see Figure 2) to compare and contrast these results with Fall 2020 (see Figure 3). While the 2020 digital version on Padlet includes work from all 15 students, I have only included one group's work from Fall 2019. Student names have been redacted to protect their identities. It should be noted that students in 2019 were asked to do the group poster in class but I ask students to do their educational chronicles prior to doing the group work. Usually, I provide my educational chronicle example a week in advance in class using the document camera.

While each student was able to create an educational chronicle, and some students made meaningful comments on Padlet about their peers, the metaphor of the river was lost. The traditional lesson with poster paper and felt pens seems a better fit for this activity. Also, it is noteworthy that most of the students copied my educational chronicle example, which was simply a timeline of dates, and events, even though I told students, they were free to choose a completely different style, rather than the linear-sequential example I provided. It is interesting to compare this result with that of last year's students. One advantage of Padlet is that while the gallery walk around to view peers work and comments given in person has to be done during class time, in the digital Padlet way of doing this lesson, the students have more time to read, and make comments. So, if I could find a way to digitally and graphically accomplish the same results as the felt pens and posters, I think that would be excellent. This is something for further research and discussion.

In sum, the pivot to alternate modes of delivery in 2020 and 2021, has had a profound impact on my teaching. My signature lessons have been forever changed and further refined as I have discovered new ways to actively engage students, especially those at a distance, in meaningful learning. These lessons serve as working examples of how to use self-study utilizing the help of a critical friend, to improve both online learning and f2f instruction. There are significant implications for all teachers.
The challenges that arose as a result of the COVID-19 pandemic resulted in excellent learning opportunities for both teachers and students.

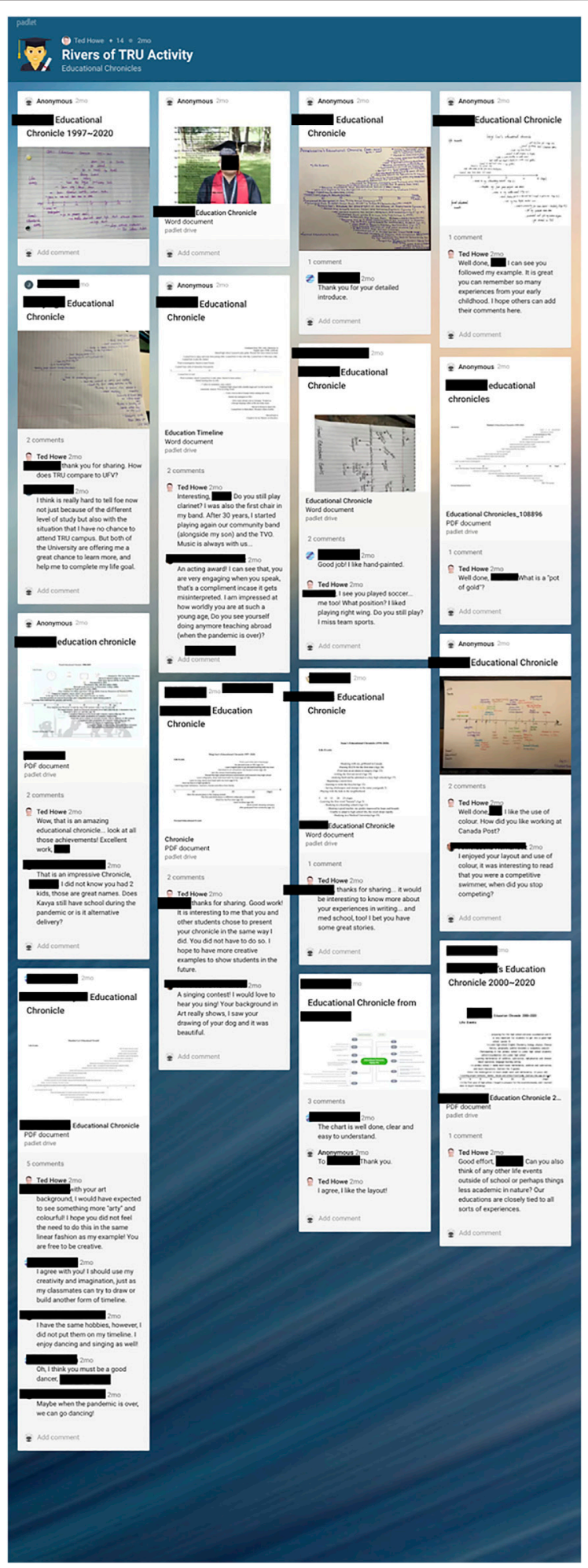

FIGURE 3 | Educational chronicle TRU rivers 2020. 


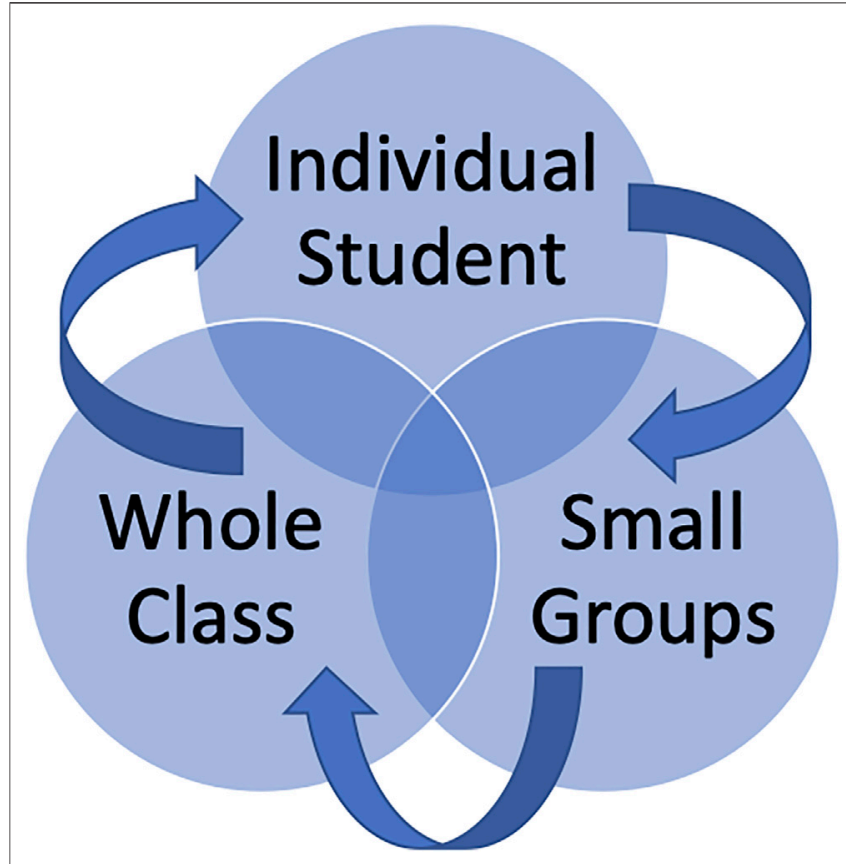

FIGURE 4 | Think, group, share.

\section{DISCUSSION}

This study illustrates how important it is to actively engage students in synchronous learning in an online classroom. Nevertheless, many of these teaching strategies can translate well into a $\mathrm{f} 2 \mathrm{f}$ or hybrid classroom. Some of these teaching strategies could also be utilized in a flipped classroom, where students do much of the work prior to the synchronous learning (either f $2 \mathrm{f}$ or online). In any class, whether it is $\mathrm{f} 2 \mathrm{f}$ or online, students must be given opportunities to engage with the curriculum, to collaborate with others and to share their thinking in a safe environment. This can be accomplished by using small groups to help facilitate their thinking and to give them the chance to practice articulating their ideas with peers before attempting to share with the entire class and the teacher. In a sense, this is a variation of the classic, Think, Pair, Share (TPS) model practiced by many teachers. I am calling this, Think, Group, Share (TGS). I have chosen to illustrate this pedagogical framework, found across all the lessons shared here using a simple Venn diagram. As shown in Figure 4, the individual overlaps and intersects with small group and whole class activities.

Another feature of promising pedagogies is that they each provide some form of scaffolding for the students. This is especially important for our international students who are particularly vulnerable in alternate delivery modes of learning. This self-study has shown that it is important to foster an online community to actively engage students and to provide opportunities for collaboration, reflection, and communication. Murdock and Williams (2011) posit ten principles for creating this community online:

1. Developing course assignments to promote collaboration among students and with the instructor;

2. Encouraging students to take leadership roles throughout the course;
3. Providing students to share their own experiences related to the course material;

4. Sharing their own experiences with students;

5. Incorporating reflective writing assignments into the course;

6. Using group projects to promote collaboration;

7. Encouraging responsibility among students for their own learning;

8. Creating assignments that encourage active learning;

9. Communicating High Expectation; and

10. Developing an environment where constructive feedback is both welcomed and solicited (p. 310).

These principles are closely aligned with the COI framework, and the repetitive theme of presence in the online learning environment (Garrison et al., 2001; Thomas, 2020).

Finally, in must be noted that not all these lessons were successful. I am still searching for a way to do the TRU Rivers in alternate forms of delivery. I think it is difficult to replace some of these tactile lessons. There is nothing like physically being together, in a $\mathrm{f} 2 \mathrm{f}$ classroom, working in groups and using posters and felt pens!

While there is a growing body of literature about the challenges facing teachers as a result of the COVID-19 pandemic, there is a paucity of empirical studies analyzing this phenomenon. Moreover, there remains a gap in the literature to connect theories of online learning with the sudden pivot to alternate modes of instruction. It is hoped that this study has provided some insights into promising pedagogies. It is a modest step to helping teachers to find their way through the pandemic and beyond.

\section{DATA AVAILABILITY STATEMENT}

The raw data supporting the conclusion of this article will be made available by the authors, without undue reservation.

\section{ETHICS STATEMENT}

The studies involving human participants were reviewed and approved by Thompson Rivers University Ethics Review Board. The patients/participants provided their written informed consent to participate in this study.

\section{AUTHOR CONTRIBUTIONS}

All authors listed have made a substantial, direct, and intellectual contribution to the work and approved it for publication.

\section{SUPPLEMENTARY MATERIAL}

The Supplementary Material for this article can be found online at: https://www.frontiersin.org/articles/10.3389/feduc.2021.661513/ full\#supplementary-material 


\section{REFERENCES}

Allo, M. D. G. (2020). Is the Online Learning Good in the Midst of COVID-19 Pandemic? the Case of EFL Learners. J. Sinestesia 10, 1-10. Available at: https:// sinestesia.pustaka.my.id/journal/article/view/24.

Anderson, T., Rourke, L., Garrison, R., and Archer, W. (2001). Assessing Teaching Presence in a Computer Conferencing Context. Olj 5 (2), 1-17. doi:10.24059/ olj.v5i2.1875

Brookfield, S. D. (2017). Becoming a Critically Reflective Teacher. 2nd ed. San Francisco, CA: Jossey-Bass, 61-78.Chapter 4: The Four Lenses of Critical Reflection

Bullock, S. M. (2020). "Navigating the Pressures of Self-Study Methodology," in 2nd International Handbook of Self-Study of Teaching and Teacher Education Practices. Editors J. Kitchen, A. Berry, S. M. Bullock, A. R. Crowe, M. Taylor, H. Guðjónsdóttir, et al. (Springer International Handbooks of EducationSpringer), 245-267. doi:10.1007/978-981-13-6880-6_8

Bullock, S. M., and Peercy, M. M. (2018). "Crossing Boundaries to challenge the Self-Study Methodology: Affordances and Critiques," in Pushing Boundaries and Crossing Borders: Self-Study as a Means for Researching Pedagogy. Editor D. G. A. Ovens (S-STEP, 19-25.

Burns, D., Dagnall, N., and Holt, M. (2020). Assessing the Impact of the COVID-19 Pandemic on Student Wellbeing at Universities in the United Kingdom: A Conceptual Analysis. Front. Educ. 5, 582882. doi:10.3389/feduc.2020.582882

Butler, B. M., and Branyon, A. (2020). Who Does Self-Study and Why? In J. Kitchen, A. Berry, S. M. Bullock, A. R. Crowe, M. Taylor, H. Guðjónsdóttir, et al. (Eds.), 2nd International Handbook of Self-Study of Teaching and Teacher Education (pp. 1-42). Springer International Handbooks of Education. Springer. doi:10.1007/978-981-13-1710-1_5-1

Cameron-Standerford, A., Menard, K., Edge, C., Bergh, B., Shayter, A., Smith, K., et al. (2020). The Phenomenon of Moving to Online/distance Delivery as a Result of COVID-19: Exploring Initial Perceptions of Higher Education Faculty at a Rural Midwestern university. Front. Educ. 5, 583881. doi:10.3389/feduc. 2020.583881

Clandinin, D. J., and Connelly, F. M. (2000). Narrative Inquiry: Experience and Story in Qualitative Research. Jossey-Bass.

Clandinin, D. J., Huber, J., Huber, M., Murphy, M. S., Orr, A. M., Pearce, M., et al. (2006). Composing Diverse Identities: Narrative Inquiries into the Interwoven Lives of Children and Teachers. Routledge. doi:10.4324/9780203012468

Clandinin, D. J. (2000). Learning to Teach: A Question of Knowledge. Edu. Can. 40 (1), 28.

Coman, C., Ţîru, L. G., Meseşan-Schmitz, L., Stanciu, C., and Bularca, M. C. (2020). Online Teaching and Learning in Higher Education during the Coronavirus Pandemic: Students' Perspective. Sustainability 12, 10367. doi:10.3390/ su122410367

Connelly, F. M., and Clandinin, D. J. (1990). Stories of Experience and Narrative Inquiry. Educ. Res. 19 (5), 2-14. doi:10.3102/0013189x019005002

Connelly, F. M., and Clandinin, D. J. (1988). Teachers as Curriculum Planners: Narratives of Experience. Teachers College: Columbia University.

Craig, C. J., and Curtis, G. A. (2020). "Theoretical Roots of Self-Study Research," in 2nd International Handbook of Self-Study of Teaching and Teacher Education Practices. Editors J. Kitchen, A. Berry, S. M. Bullock, A. R. Crowe, M. Taylor, H. Guðjónsdóttir, et al. (Springer International Handbooks of Education, Springer), 57-96. doi:10.1007/978-981-13-6880-6_3

Craig, C. J. (2008). Joseph Schwab, Self-Study of Teaching and Teacher Education Practices Proponent? A Personal Perspective. Teach. Teach. Edu. 24 (8), 1993-2001. Available at: https://www.scopus.com/inward/record.url?eid=2s2.0-50849108512\&partnerID=40\&md5=1e6a4b8678debb771634e63e30231182. doi:10.1016/j.tate.2008.05.008

Dewey, J. (1938). Experience and Education. Collier books.

D. J. Clandinin (2007). in Handbook of Narrative Inquiry: Mapping a Methodology (Sage Publications).

Downes, S. (2005). Connectivism and Connective Knowledge. Learn. Organ. J. 12 (5). Available at: https://www.downes.ca/files/books/Connective_Knowledge19May2012.pdf. doi:10.1108/09696470510700394

Ellis, C. S., and Bochner, A. (2000). "Autoethnography, Personal Narrative, Reflexivity: Researcher as Subject," in The Handbook of Qualitative
Research. Editors N. Denzin and Y. Lincoln (Sage), 733-768. Available at: http://works.bepress.com/carolyn_ellis/49/.

Etherington, K. (2006). "Reflexivity: Using Our 'selves' in Narrative Research," in Narrative Reasearch on Learning: Comparative and International Perspectives. Editor S. Trahar (Symposium Books), 77-92.

Garbett, D., Fitzgerald, L. M., and Thomas, L. (2020). “Tracing Self-Study Research through Biennial Castle Conferences at Herstmonceux," in 2nd International Handbook of Self-Study of Teaching and Teacher Education Practices. Editors J. Kitchen, A. Berry, S. M. Bullock, A. R. Crowe, M. Taylor, H. Guðjónsdóttir, et al. (Springer International Handbooks of Education, Springer), 15-55. doi:10. 1007/978-981-13-6880-6_2

Garrison, D. R., Anderson, T., and Archer, W. (2001). Critical Thinking, Cognitive Presence, and Computer Conferencing in Distance Education. Am. J. Distance Edu., 15(1), 7-23. doi:10.1080/08923640109527071

Glaser, B. G., and Strauss, A. L. (1967). The Discovery of Grounded Theory: Strategies for Qualitative Research. Wawthorne, NY: Aldine De Gruyter.

Goldie, J. G. S. (2016). Connectivism: a Knowledge Learning Theory for the Digital Age?. Med. Teach. 38 (10), 1064-1069. Available at: http://eprints.gla.ac.uk/ 118043/9/118043.pdf. doi:10.3109/0142159x.2016.1173661

Hamilton, M. L., Hutchinson, D. A., and Pinnegar, S. (2020). Quality, Trustworthiness, and S-STTEP Research. In J. Kitchen, A. Berry, S. M. Bullock, A. R. Crowe, M. Taylor, H. Guðjónsdóttir, et al. (Eds.), 2nd International Handbook of Self-Study of Teaching and Teacher Education Practices (pp. 299-338). Springer International Handbooks of Education, Springer. doi:10.1007/978-981-13-6880-6_10

Howe, E. R. (2010). “A Comparative Ethnographic Narrative Approach to Studying Teacher Acculturation," in Papers in Memory of David N. Wilson: Clamouring for a Better World. Editors V. L. Masemann and S. Majhanovich (Sense Publishers), 121-136.

Howe, E. R., and Cope Watson, G. (2020). "S-STEP in Comparative and International Education: Comparative Ethnographic Narrative," in Textiles and Tapestries. Editors C. Edge, A. Cameron-Standerford, and B. Bergh (EdTech Books. ). Available at: https://edtechbooks.org/textiles_tapestries_ self_study/chapter_116.

Howe, E. R. (2005). Japan's Teacher Acculturation: Critical Analysis through Comparative Ethnographic Narrative. J. Edu. Teach. 31 (2), 121-131. doi:10. 1080/02607470500127251

Howe, E. R., and Xu, S. (2013). Transcultural Teacher Development within the Dialectic of the Global and Local: Bridging Gaps between East and West. Teach. Teach. Edu. 36, 33-43. doi:10.1016/j.tate.2013.06.010

Johnson, N., Veletsianos, G., and Seaman, J. (2020). U.S. Faculty and Administrators' Experiences and Approaches in the Early Weeks of the COVID-19 Pandemic. Olj, 24(2), 6-21. doi:10.24059/olj.v24i2.2285

Jones, A. L., and Kessler, M. A. (2020). Teachers' Emotion and Identity Work during a Pandemic. Front. Edu. 5, 583775. doi:10.3389/educ.2020.59557410. 3389/feduc. 2020.583775

Kitchen, J., Berry, A., Bullock, S. M., Crowe, A. R., Taylor, M., Guðjónsdóttir, H., et al. (2020). 2nd International Handbook Of Self-Study Of Teaching And Teacher Education Practices. Second Edition. Springer International Handbooks of Education, Springer. doi:10.1007/978-981-13-1710-1

Kitchen, J. (2009). Passages: Improving Teacher Education through Narrative SelfStudy, Research Ethods for the Self-Study of Practice. Springer, 35-51. doi:10. 1007/978-1-4020-9514-6_3

Kosnik, C., and Beck, C. (2010). Redesigning a Teacher Education Program: A story of Our Challenges and Successes. Conference Paper Proceedings of the 8th International Conference on Self-Study of Teacher Education PracticesNavigating the Public and Private: Negotiating the Diverse Landscape of Teacher Education. East Sussex, England.

LaBoskey, V. K. (2004). "The Methodology of Self-Study and its Theoretical Underpinnings," in International Handbook of Self-Study of Teaching and Teacher Education Practices. Editors J. J. Loughran, M. L. Hamilton, V. K. LaBoskey, and T. Russell (Springer), 817-869. doi:10.1007/978-14020-6545-3_21

Loose, C. C., and Ryan, M. G. (2020). Cultivating Teachers when the School Doors Are Shut: Two Teacher-Educators Reflect on Supervision, Instruction, Change and Opportunity during the COVID-19 Pandemic. Front. Educ. 5, 582561. doi:10.3389/feduc. 2020.582561 
Loughran, J., Hamilton, M. L., LaBoskey, V. K., and Russell, T. (2004). International Handbook of Self-Study of Teaching and Teacher Education Practices. Springer. doi:10.4324/9780203018637

Loughran, J. J. (2020). Forward. In J. Kitchen, A. Berry, S. M. Bullock, A. R. Crowe, M. Taylor, H. Guðjónsdóttir, et al. (Eds.), 2nd International Handbook of SelfStudy of Teaching and Teacher Education Practices Second Edition (pp. v-x). Springer International Handbooks of Education, Springer. doi:10.1007/978981-13-6880-6

Loughran, J. (2007). Researching Teacher Education Practices. J. Teach. Edu. 58 (1), 12-20. doi:10.1177/0022487106296217

Loughran, J. (2010). Seeking Knowledge for Teaching Teaching: Moving beyond Stories. Studying Teach. Edu. 6 (3), 221-226. doi:10.1080/17425964.2010.518490

McCormack, M. (2020). EDUCAUSE QuickPoll Results: Fall Readiness for Teaching and Learning. EDUCAUSE Rev. 18.September

Mena, J., and Russell, T. (2017). Collaboration, Multiple Methods, Trustworthiness: Issues Arising from the 2014 International Conference on Self-Study of Teacher Education Practices. Studying Teach. Edu. 13 (1), 105-122. doi:10.1080/17425964.2017.1287694

Moore, M. G. (1989). Editorial: Three Types of Interaction. Am. J. Distance Edu. 3, 1-7. doi:10.1080/08923648909526659

Moore, M. G. (2012). "The Theory of Transactional Distance," in Handbook of Distance Education. Editor M. G. Moore (L. Erlbaum Associates).

Murdock, J. L., and Williams, A. M. (2011). Creating an Online Learning Community: Is it Possible?. Innov. High Educ. 36, 305-315. doi:10.1007/ x10755-011-9188-610.1007/s10755-011-9188-6

Prince, M., Felder, R., and Brent, R. (2020). Active Student Engagement in Online STEM Classes: Approaches and Recommendations. Adv. Eng. Edu. 8 (4), 1-23.

Rapanta, C., Botturi, L., Goodyear, P., Guàrdia, L., and Koole, M. (2020). Online university Teaching during and after the COVID-19 Crisis: Refocusing Teacher Presence and Learning Activity. Postdigit Sci. Educ. 2, 923-945. doi:10.1007/ s42438-020-00155-y

Samaras, A. P., and Sell, C. (2013). Please Write: Using Critical Friend Letters in Teacher Research. Teach. Edu. Q. 40 (4), 93-109.
Schuck, S., and Russell, T. (2005). Self-study, Critical friendship, and the Complexities of Teacher Education. Studying Teach. Edu. 1 (2), 107-121. doi:10.1080/17425960500288291

Schwab, J. J. (1983). The Practical 4: Something for Curriculum Professors to Do. Curriculum Inq. 13 (3), 239-265. doi:10.1080/03626784.1983.11075885

Siemens, G. (2005). Connectivism: A Learning Theory for the Digital Age. Int. J. Instructional Tech. Distance Learn. 2 (1), 3-10. Available at: https://pdfs. semanticscholar.org/a25f/84bc55488d01bd5f5acac4eed0c7d8f4597c.pdf? _ga=2.124207119.46229956.1593962178-757212093.1593962178.

Stewart, A. (1998). The Ethnographer's Method, 46. Sage.

Thomas, M. B. (2020). Virtual Teaching in the Time of COVID-19: Rethinking Our WEIRD Pedagogical Commitments to Teacher Education. Front. Educ. 5, 595574. doi:10.3389/feduc.2020.595574

Vanassche, E., and Berry, A. (2020). Teacher Educator Knowledge, Practice, and S-STTEP Research. In J. Kitchen, A. Berry, S. M. Bullock, A. R. Crowe, M. Taylor, H. Guðjónsdóttir, et al. (Eds.), 2nd International Handbook Of Self-Study Of Teaching And Teacher Education Practices Second Edition (pp. 177-213). Springer International Handbooks of Education, Springer. doi:10. 1007/978-981-13-6880-6_6

Yonemura, M. (1982). Teacher Conversations: A Potential Source of Their Own Professional Growth. Curriculum Inq. 12 (3), 239-256. doi:10.1080/03626784. 1982.11075842

Conflict of Interest: The authors declare that the research was conducted in the absence of any commercial or financial relationships that could be construed as a potential conflict of interest.

Copyright (c) 2021 Howe and Watson. This is an open-access article distributed under the terms of the Creative Commons Attribution License (CC BY). The use, distribution or reproduction in other forums is permitted, provided the original author(s) and the copyright owner(s) are credited and that the original publication in this journal is cited, in accordance with accepted academic practice. No use, distribution or reproduction is permitted which does not comply with these terms. 